\title{
The Use of Copper(I) Halides as a Preparative Tool
}

\author{
Arno Pfitzner*[a] \\ Dedicated to Professor Arndt Simon on the occasion of his 60th birthday
}

\begin{abstract}
The use of copper(I) halides as a preparative tool is discussed with respect to the synthesis of adduct compounds with new polymeric and oligomeric main group molecules. By using this approach new polymers of main group elements-some of which have been predicted by theoretical investigations - can be obtained in a crystalline state and are therefore accessible for a basic structural characterization. Thus, it becomes possible to compare the structural data, experimental data, and theoretical results. Mixed copper halide chalcogenides are accessible when complex copper thiometalates and copper halides are combined. These solid-state compounds are of special interest since they provide experimental access to new main group molecules. In addition, they exhibit a high copper ion conductivity when certain structural features are present in the compounds. A survey is given of basic synthetic and general structural aspects.
\end{abstract}

Keywords: chalcogens - copper $\cdot$ ion conductors • phosphorus

\section{Introduction}

The design of new copper ion-conducting materials requires both structural and chemical prerequisites. From a chemical viewpoint, weakly bonded and/or highly polarizable bonding partners for the mobile ions are necessary to provide easy jumps from one site to another. This reveals the most important structural prerequisite, namely a large number of positions which energetically are almost equal. In addition, these positions have to be separated only by small energy barriers, for example, by common faces of the coordination polyhedra of the mobile ions. To determine the optimum chemical composition and structural arrangements, we started

[a] Priv.-Doz. Dr. A. Pfitzner

Anorganische Chemie

Universität Siegen

57068 Siegen (Germany)

Fax: (+49)271-740 2555

E-mail:pfitzner@chemie.uni-siegen.de to examine compounds that can be considered as adducts of copper(I) halides and neutral polymers of main group elements. These investigations were based on earlier publications describing materials that all have a common building principle. Nevertheless, their chemical description was quite different in the past and changed from time to time. A comparison of compounds such as $\mathrm{CuXTe}(\mathrm{X}=\mathrm{Cl}, \mathrm{Br}, \mathrm{I}){ }^{[1]}$ $\mathrm{CuClSe}_{2}$ and $\mathrm{CuXTe}_{2}(\mathrm{X}=\mathrm{Cl}, \mathrm{Br}, \mathrm{I}),{ }^{[2]} \mathrm{CuXSe}_{3}(\mathrm{X}=\mathrm{Br}, \mathrm{I}),{ }^{\left[{ }^{3]}\right.}$ $\mathrm{Cu}_{1.98} \mathrm{P}_{3} \mathrm{I}_{2},{ }^{[4]}$ and $\mathrm{CuBrS}_{4} \mathrm{~N}_{4}{ }^{[5]}$ reveals their basic composition; they consist of formally neutral molecules of main group elements embedded in a copper(I) halide (the copper halide matrix). Since some of these solids, namely $\mathrm{CuXTe}$ and $\mathrm{Cu}_{1.98} \mathrm{P}_{3} \mathrm{I}_{2}$, showed an enhanced ionic conductivity, ${ }^{[\mathrm{b}, 4]}$ we started to use the copper(I) halide matrix as a general synthetic tool for the synthesis of a novel group of ion-conducting materials. In the course of these investigations the copper(I) halides turned out to be a helpful preparative tool. These compounds are formulated herein as consisting of a copper halide part and of a molecular or a copper thiometalate part in order to highlight the chemical relationships between these compounds. This approach leads to a general survey and a basic understanding of their chemical similarities even if it might be confusing when only one of the compounds is discussed. The discussion here is restricted to those compounds that have been crystallographically characterized.

\section{The General Synthetic Approach}

Some of the copper(I) halide chalcogen compounds reported previously were obtained by hydrothermal reactions from mineral acids; a survey is given in ref.[6]. All compounds under discussion herein may also be obtained by solid-state reactions from stoichiometric mixtures of copper halides and the corresponding reaction partners. The advantage of the solid-state chemical route is that the reaction products are usually obtained as pure materials. In contrast, hydrothermal syntheses very often result in mixtures of different compounds. Thus, the determination of physical properties, for example, ionic conductivities, becomes difficult. Commercially available copper halides $\mathrm{CuX}$ are purified by recrystallization from a saturated solution of $\mathrm{CuX}$ in the corresponding mineral acid. Elemental copper is freshly reduced in a 
hydrogen stream at $650^{\circ} \mathrm{C}$. The starting materials are melted in evacuated silica ampoules and are then annealed approximately $50^{\circ} \mathrm{C}$ below the melting point or the decomposition temperature of the reaction product. Experimental details are available in the relevant cited literature. Most of the compounds that are described here can be regarded to be thermodynamically stable. The only exception is $\mathrm{CuBrSe}_{2}$ which is metastable and needs a special preparational procedure. The phosphorus-rich samples, in particular, have to be heated slowly because otherwise the silica tubes containing the reaction mixtures tend to explode, especially when white phosphorus is used instead of red phosphorus.

\section{Phosphorus Polymers and Phosphochalcogenides}

$\mathrm{Cu}_{1.98} \mathrm{P}_{3} \mathrm{I}_{2}{ }^{[4]}$ is denoted as $(\mathrm{CuI})_{8} \mathrm{P}_{12}$ throughout this article to emphasize its adduct character. $(\mathrm{CuI})_{8} \mathrm{P}_{12}$ was the first compound of a formally neutral phosphorus polymer embedded in a copper halide matrix. $(\mathrm{CuI})_{3} \mathrm{P}_{12}{ }^{[7]}$ and $(\mathrm{CuI})_{2} \mathrm{P}_{14}{ }^{[8]}$ could also be prepared by using copper iodide as solid solvent for phosphorus. These compounds consist of neutral phosphorus strands embedded in copper iodide. Figure 1 shows the

a)

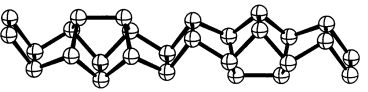

b)

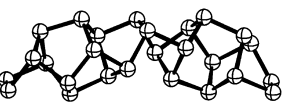

c)
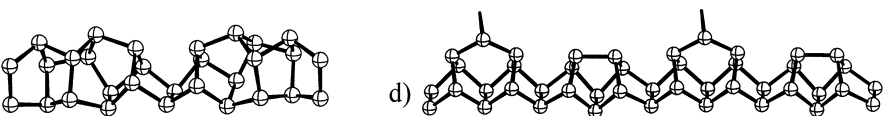

Figure 1. The phosphorus strands found in a) $(\mathrm{CuI})_{8} \mathrm{P}_{12}$, b) $(\mathrm{CuI})_{3} \mathrm{P}_{12}$, c) $(\mathrm{CuI})_{2} \mathrm{P}_{14}$, and d) Hittorf's phosphorus. Note that all phosphorus atoms are three-bonded in these neutral polymers.

phosphorus tubes which can be denoted as ${ }_{\infty}^{1}\left([\mathrm{P} 8] \mathrm{P} 4(4)[)^{0}\right.$ in $(\mathrm{CuI})_{8} \mathrm{P}_{12},{ }_{\infty}^{1}\left([\mathrm{P} 10] \mathrm{P} 2[)^{0}\right.$ in $(\mathrm{CuI})_{3} \mathrm{P}_{12}$, and ${ }_{\infty}^{1}\left([\mathrm{P} 12(4)] \mathrm{P} 2[)^{0}\right.$ in $(\mathrm{CuI})_{2} \mathrm{P}_{14}$. The corresponding phosphorus polymers, their stabilities, and also a rational nomenclature were subject of a theoretical study. ${ }^{[9]}$ According to these calculations the stability of ${ }_{\infty}^{1}\left([\mathrm{P} 10] \mathrm{P} 2[)^{0}\right.$ corresponds to that of ${ }_{\infty}^{1}(] \mathrm{P} 2[\mathrm{P} 8]-$ $\mathrm{P} 2[\mathrm{P} 9])^{0}$, the phosphorus strand in Hittorf's phosphorus, ${ }^{[10]}$ see Figure $1 \mathrm{~d}$. The helical shape of the polymer ${ }_{\infty}^{1}\left([\mathrm{P} 10] \mathrm{P} 2[)^{0}\right.$ and the resulting difficulties to pack these helices effectively can be regarded as the major reason why it has not yet been detected as a crystalline pure allotrope of elemental phosphorus. By contrast, the tubes ${ }_{\infty}^{1}\left([\mathrm{P} 8] \mathrm{P} 4(4)[)^{0}\right.$ and ${ }_{\infty}^{1}([\mathrm{P} 12(4)]-$ $\mathrm{P} 2[)^{0}$ were calculated to have a somewhat smaller stability. Nevertheless both of them can also be obtained in copper iodide as solid solvent. This might lead to the assumption that the coordination of copper ions to the phosphorus strands provides some energetical stabilization. However, a closer inspection of the crystal structures of these compounds (Figure 2) shows that the number of $\mathrm{Cu}-\mathrm{P}$ bonds is limited to a few phosphorus atoms per translational unit and therefore the stabilization effect is supposed to be only a small one. This is impressively demonstrated by $(\mathrm{CuI})_{2} \mathrm{P}_{14}$ where only five of 14 phosphorus atoms are bonded to copper. $(\mathrm{CuI})_{3} \mathrm{P}_{12}$ contains two crystallograhically different phosphorus tubes ${ }_{\infty}^{1}\left([\mathrm{P} 10] \mathrm{P} 2[)^{0}\right.$. One of them even has only three $\mathrm{Cu}-\mathrm{P}$ bonds
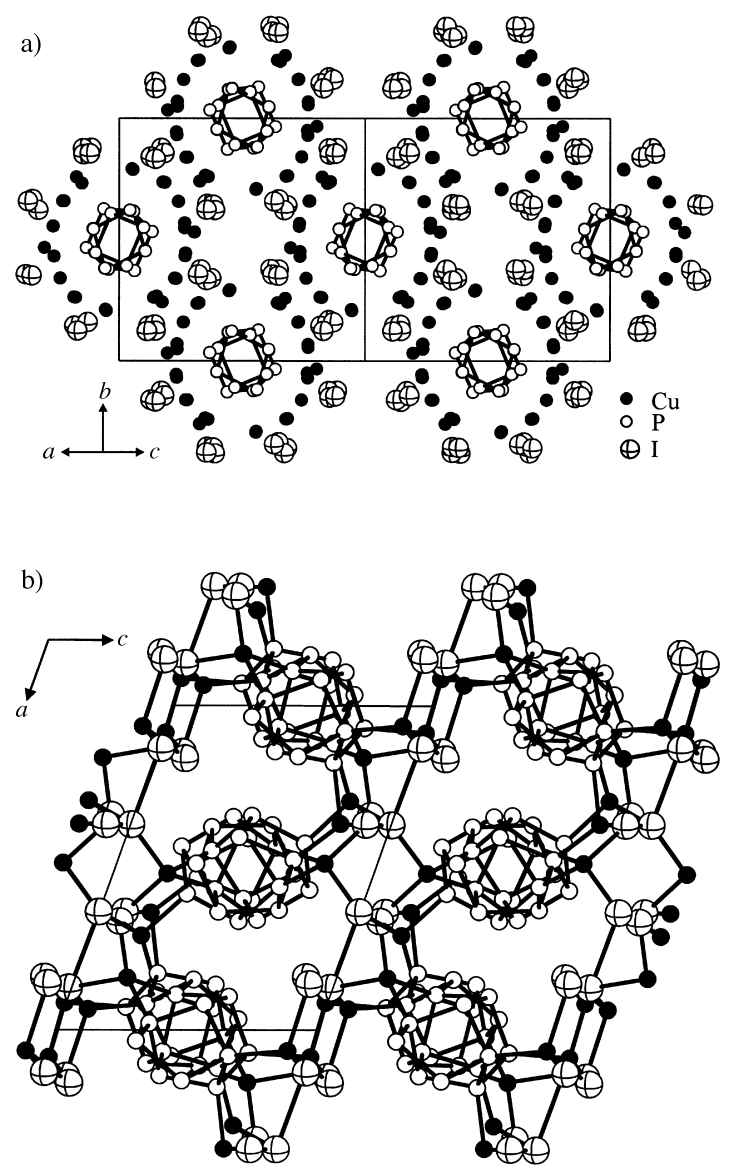

c)

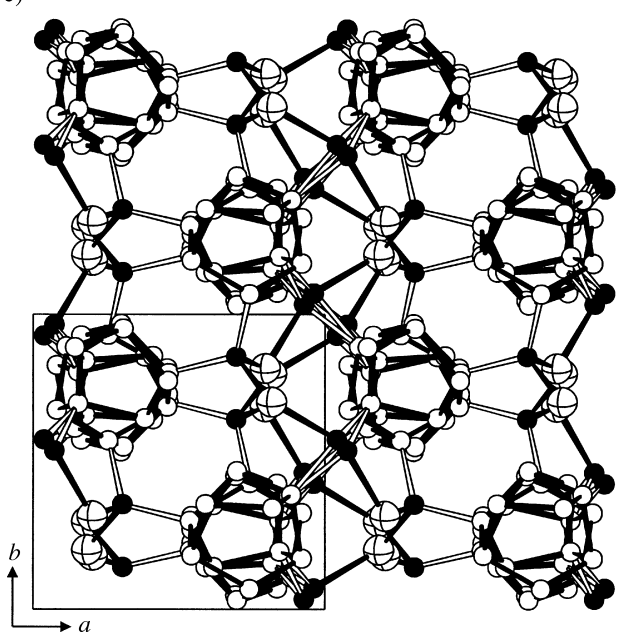

Figure 2. The crystal structures of a) $(\mathrm{CuI})_{8} \mathrm{P}_{12}$ (data taken from ref. [4]), b) $(\mathrm{CuI})_{3} \mathrm{P}_{12}$, and c) $(\mathrm{CuI})_{2} \mathrm{P}_{14}$. The pronounced disorder of the copper atoms in $(\mathrm{CuI})_{8} \mathrm{P}_{12}$ has to be taken into account. The copper positions are not fully occupied. A similar situation is found for $(\mathrm{CuI})_{2} \mathrm{P}_{14}$ in which one of the copper positions is split into two almost equally occupied sites.

per 12 phosphorus atoms, whereas the other has five $\mathrm{Cu}-\mathrm{P}$ bonds per 12 phosphorus atoms. In case of $(\mathrm{CuI})_{8} \mathrm{P}_{12}$ this analysis is somewhat difficult since the copper atoms are highly disordered in this compound. Thus, all phosphorus atoms can be regarded as being bonded to copper atoms despite the fact that only eight copper atoms are available for 
twelve phosphorus atoms. The distances $d(\mathrm{Cu}-\mathrm{P})$ of $2.3 \AA$ are about the same or even shorter than in binary copper phosphides, for example, in $\mathrm{Cu}_{2} \mathrm{P}_{7}$ or in $\mathrm{CuP}_{2} \cdot{ }^{[11]}$

Besides the above-mentioned formally neutral polymers also polyphosphide ions with low charges could be obtained in a copper halide matrix. In addition to some structurally not well defined compounds, we determined the crystal structures and the chemical compositions of $(\mathrm{CuI})_{2} \mathrm{CuP}_{15}{ }^{[12]}$ and of $(\mathrm{CuBr}){ }_{10} \mathrm{Cu}_{2} \mathrm{P}_{20} \cdot{ }^{[13]} \mathrm{A}$ comparable polyphosphide ion $\mathrm{P}_{15}{ }^{1-}$ was also observed in several alkali metal polyphoshides with the general composition $\mathrm{AP}_{15}{ }^{[14]}$ The corresponding phosphorus polymers are shown in Figure 3. The basic building principle

a)
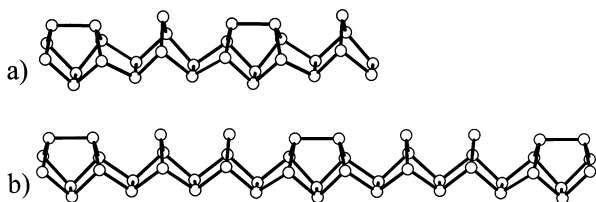

Figure 3. Polyphosphide ions a) ${ }_{\infty}^{1}\left[\mathrm{P}_{15}{ }^{1-}\right]$ in $(\mathrm{CuI})_{2} \mathrm{CuP}_{15}$, and b) ${ }_{\infty}^{1}\left[\mathrm{P}_{20}{ }^{2-}\right]$ in $(\mathrm{CuBr})_{10} \mathrm{Cu}_{2} \mathrm{P}_{20}$. Both polymers consist of [P8] units which are separated by norbornane analogous $\left[\mathrm{P}_{7}\right]$ units. The negative charges are located on the two-bonded $\mathrm{P}$ atoms.

of these polyanions, which consist of [P8] cages separated by negatively charged norbornane-analogous ]P2[P3]P2[ units, may lead to the assumption that also a neutral polymer consisting exclusively of [P8] cages and ]P2[ bridges or a polyanion formed by alternating] 2 2 [ and [P3] units, that is, a one-dimensional polymer ${ }_{\infty}^{1}\left(\mathrm{P}_{5}{ }^{1-}\right)$, might exist. However, despite some experimental hints neither the neutral strand nor the polyanion could yet be detected. ${ }^{[15]}$ In the case of $\mathrm{TlP}_{5}$ the polyanions $\left(\mathrm{P}_{5}{ }^{1-}\right)$ are two-dimensional. ${ }^{[16]}$ Figure 4 shows that the cross-section of the polyanionic tubes resembles closely that of the neutral strands in Hittorf's phosphorus, that is, it looks like a pentagon. Two phosphorus tubes are interlinked by copper atoms to form double tubes in these two copper halide phosphorus adducts. Those phosphorus atoms which have only two covalent bonds to other phosphorus atoms are additionally bonded to two copper atoms $(d(\mathrm{P}-\mathrm{Cu}) \approx 2.29 \AA)$. Thus, a tetrahedral environment results for them.

Besides these neutral and low-charged phosphorus polymers also neutral phosphochalcogenide molecules can be obtained in a copper halide matrix. These molecules form polymers in $(\mathrm{CuI})_{5} \mathrm{P}_{16} \mathrm{Q}$ and in $(\mathrm{CuI})_{2} \mathrm{P}_{4-y} \mathrm{Q}_{x}(\mathrm{Q}=\mathrm{S}, \mathrm{Se}) .{ }^{[15,17]}$ A first example of a well-characterized oligomeric phosphochalcogenide cage molecule in a copper halide matrix was recently obtained by a high-temperature reaction of catena$\left(\mathrm{P}_{4} \mathrm{Se}_{4}\right)_{x}{ }^{[18]}$ with copper iodide. At a reaction temperature of $400{ }^{\circ} \mathrm{C}$ the polymeric catena- $\left(\mathrm{P}_{4} \mathrm{Se}_{4}\right)_{x}$ decomposed and at least one of the four possible $\mathrm{P}_{4} \mathrm{Se}_{4}$ cage molecules could be isolated in a matrix of copper iodide. A so-called $\alpha$-cage (comparable to $\mathrm{As}_{4} \mathrm{~S}_{4}$ ), a $\beta$-cage, and two different $\mathrm{P}_{4} \mathrm{Se}_{3}$ cages with an additional exo-Se atom have to be distinguished. The resulting compound was $(\mathrm{CuI})_{3} \mathrm{P}_{4} \mathrm{Se}_{4} \cdot{ }^{[19]}$ Thus the $\beta$ - $\mathrm{P}_{4} \mathrm{Se}_{4}$ cage which has been controversially discussed during the past three decades ${ }^{[20-22]}$ was accessible for a complete structural characterization. The cage molecule $\beta-\mathrm{P}_{4} \mathrm{Se}_{4}$ and the crystal structure of $(\mathrm{CuI})_{3} \mathrm{P}_{4} \mathrm{Se}_{4}$ are shown in Figures 5 and 6, respectively. It
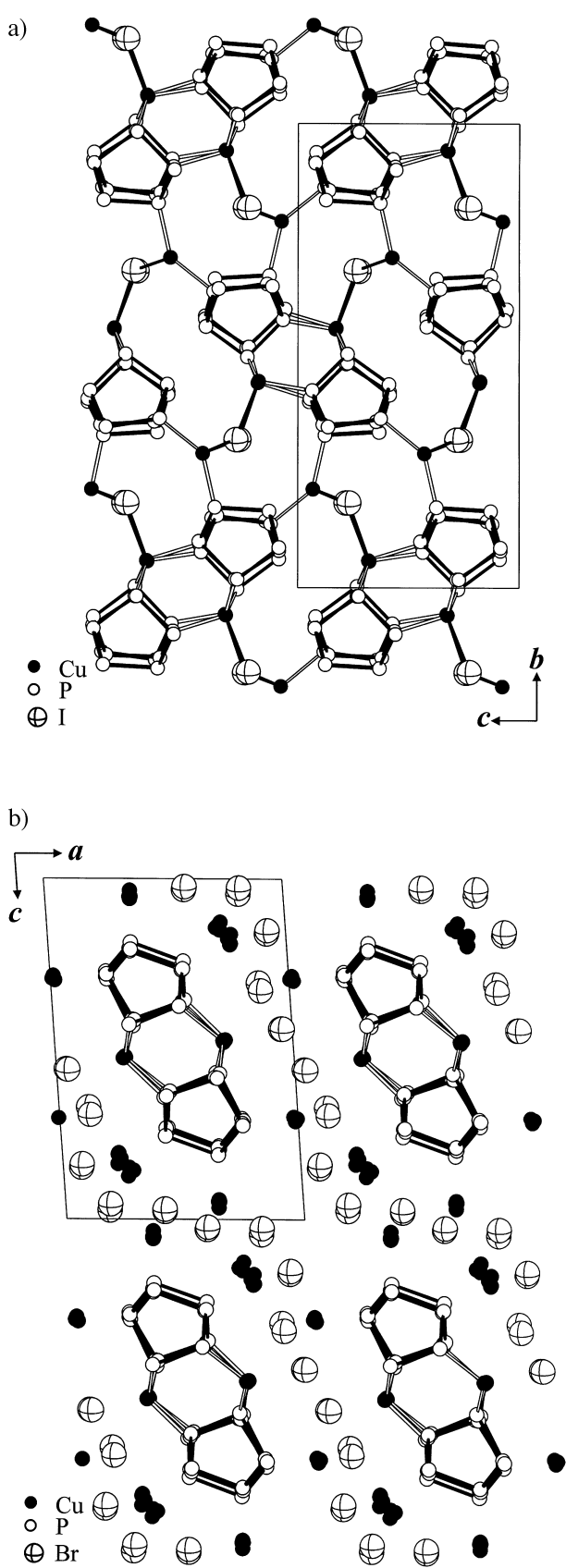

Figure 4. Crystal structures of a) $(\mathrm{CuI})_{2} \mathrm{CuP}_{15}$ and b) $(\mathrm{CuBr})_{10} \mathrm{Cu}_{2} \mathrm{P}_{20}$. Whereas the copper atoms in $(\mathrm{CuI})_{2} \mathrm{CuP}_{15}$ are well ordered they are highly disordered in $(\mathrm{CuBr})_{10} \mathrm{Cu}_{2} \mathrm{P}_{20}$.

becomes evident that stacks of the neutral molecules are surrounded by columns of copper iodide and vice versa. CuI forms an arrangement which can be regarded as a section of the wurtzite type in order to satisfy the metrical necessities of the $\mathrm{P}_{4} \mathrm{Se}_{4}$ stacks. This modification is not yet known for pure $\mathrm{CuI}$ but an arrangement of copper and iodine atoms sim-

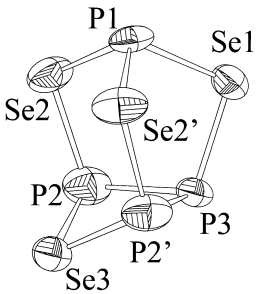

Figure 5. $\beta-\mathrm{P}_{4} \mathrm{Se}_{4}$ cage molecules as observed in $(\mathrm{CuI})_{3} \mathrm{P}_{4} \mathrm{Se}_{4}$. Ellipsoids are drawn at a $90 \%$ probability level. 


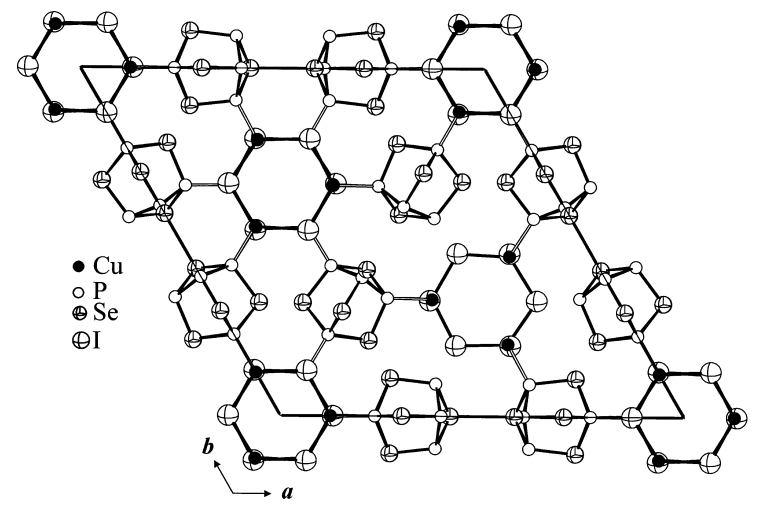

Figure 6. Section from the crystal structure of $(\mathrm{CuI})_{3} \mathrm{P}_{4} \mathrm{Se}_{4}$. Stacks of $\beta$ $\mathrm{P}_{4} \mathrm{Se}_{4}$ are surrounded by CuI, which shows an arrangement corresponding to the wurtzite-type structure.

ilar to that in $(\mathrm{CuI})_{3} \mathrm{P}_{4} \mathrm{Se}_{4}$ was also reported for $N$-methylpyrazinium-triiodocuprate(I). ${ }^{[23]} \mathrm{A}$ similar compound containing the homologous $\beta-\mathrm{P}_{4} \mathrm{~S}_{4}$ cage molecule attached to a metal halide, namely $\left(\mathrm{NbCl}_{5}\right)_{2} \mathrm{P}_{4} \mathrm{~S}_{4}$, was recently obtained. ${ }^{[2]}$ $(\mathrm{CuI})_{3} \mathrm{P}_{4} \mathrm{Se}_{4}$ can be transferred to $(\mathrm{CuI}) \mathrm{P}_{4} \mathrm{Se}_{4}$ by a chemical transport reaction using elemental iodine as the transporting agent. ${ }^{[25]}$ In this compound polymeric $\mathrm{P}_{4} \mathrm{Se}_{4}$ chain molecules are found which closely resemble the corresponding chains in catena- $\left(\mathrm{P}_{4} \mathrm{Se}_{4}\right)_{x} \cdot{ }^{[18]}$ However, the polymers have a mirror plane perpendicular to the chain axis when they are embedded in $\mathrm{CuI}$. By contrast these polymers are chiral in the pure phosphoselenide (Figure 7). Similar to $(\mathrm{CuI})_{3} \mathrm{P}_{4} \mathrm{Se}_{4}$ only some

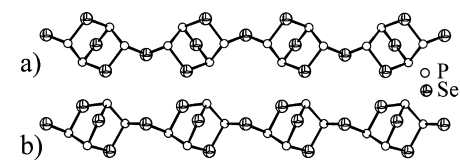

Figure 7. Polymeric $\mathrm{P}_{4} \mathrm{Se}_{4}$ chain molecules as observed in a) (CuI) $\mathrm{P}_{4} \mathrm{Se}_{4}$ and in b) catena- $\left(\mathrm{P}_{4} \mathrm{Se}_{4}\right)_{x}{ }^{[18]}$ Note that the polymers attached to $\mathrm{CuI}$ have a mirror plane perpendicular to the polymer axis, whereas the polymer chains in the free compound are chiral.

of the phosphorus atoms are bonded to copper, and no contacts are observed between copper and selenium atoms. Figure 8 shows a section of the crystal structure of $(\mathrm{CuI}) \mathrm{P}_{4} \mathrm{Se}_{4}$.

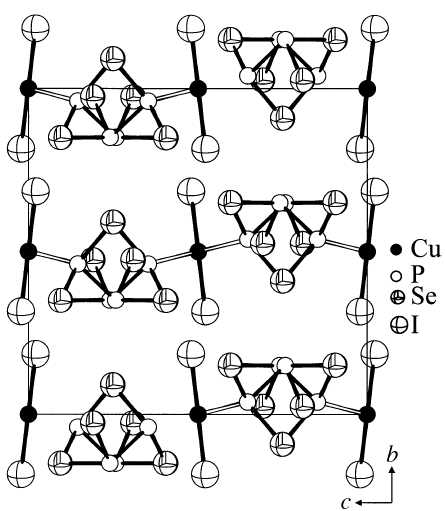

Figure 8. Section of the crystal structure of $(\mathrm{CuI}) \mathrm{P}_{4} \mathrm{Se}_{4}$. The $\mathrm{P}_{4} \mathrm{Se}_{4}$ polymers are connected by $\mathrm{CuI}$ to form layers. Only weak van der Waals bonds occur between these layers.

\section{Heteroatomic Chalcogen Molecules}

The copper halide matrix can be used to form adduct compounds with neutral selenium or tellurium chains and also with six-membered selenium rings (see Introduction). The question then arose whether also neutral heteroatomic chalcogen molecules were accessible in this type of compounds. Since two crystallographically different chalcogen positions are present in $\mathrm{CuXQ}_{2}(\mathrm{X}=\mathrm{Cl}, \mathrm{Br}, \mathrm{I}, \mathrm{Q}=\mathrm{Se}, \mathrm{Te})$ mixed heteroatomic neutral chains of the type ${ }_{\infty}^{1}\left[\mathrm{QQ}^{\prime}\right]$ can be expected in this type of adducts. Thus, $\mathrm{CuXSeTe}(\mathrm{X}=\mathrm{Cl}, \mathrm{Br}$, I) and $\mathrm{CuXSTe}(\mathrm{X}=\mathrm{Cl}, \mathrm{Br})$ exhibit almost perfectly ordered ${ }_{\infty}^{1}[\mathrm{SeTe}]$ and ${ }_{\infty}^{1}[\mathrm{STe}]$ chain molecules, respectively. ${ }^{[26,27]}$ To date no further examples for such ordered heteroatomic chalcogen chain molecules exist. The bonding interaction between the copper halides and the embedded neutral polymers is expected to be relatively weak. However, it is strong enough to arrange the polymers in an ordered threedimensional lattice. The crystal structures of isotypic $\mathrm{CuXQ}_{2}$ and $\mathrm{CuXQQ}^{\prime}$ consist of layers which are formed by the chain molecules and by the surrounding copper halide. Figure 9

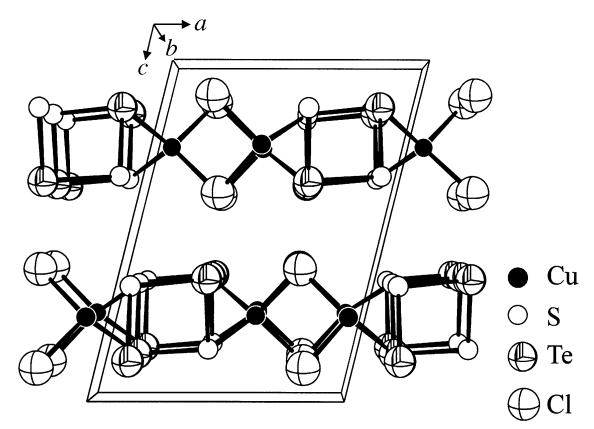

Figure 9. Crystal structure of $\mathrm{CuClSTe}$ as a representative for the series $\mathrm{CuXQQ}^{\prime}$. Note that tellurium is always located in the position which provides a short distance to a halide ion of the adjacent layer.

shows that contacts $d(\mathrm{X}-\mathrm{Q})$ are present between a halide ion of one layer and one chalcogen position of another layer which are much shorter than the corresponding van der Waals distances, for example $d(\mathrm{Cl}-\mathrm{Te})=3.173 \AA$ in CuCISTe. The chalcogen atom on this position is of course positively polarized. In case of a mixed polymer ${ }_{\infty}^{1}\left[\mathrm{QQ}^{\prime}\right]$ the heavier chalcogen atom is located preferably on this position, whereas the lighter one takes the other position.

The matrix character of the copper halides is impressively demonstrated when we consider how metastable $\mathrm{CuBrSe}_{2}$ is obtained. Only one stable compound, namely $(\mathrm{CuBr})_{2} \mathrm{Se}_{6}$, exists in the system $\mathrm{CuBr}-\mathrm{Se}$ according to phase analytical studies. ${ }^{[28]}$ Nevertheless, crystalline $\mathrm{CuBrSe}_{2}$, together with a certain amount of amorphous $\mathrm{Se}$, is obtained when a melt of $\mathrm{CuBr}$ and $\mathrm{Se}$ is cooled from about $500^{\circ} \mathrm{C}$ to room temperature over several minutes. ${ }^{[29]}$ Evidently, the selenium chains which are already present in the melt readily form metastable $\mathrm{CuBrSe}_{2}$ with the available copper bromide. When this compound is annealed at elevated temperatures it rapidly transforms to give crystalline $(\mathrm{CuBr})_{2} \mathrm{Se}_{6}$, that is, the Se chains depolymerize and $\mathrm{Se}_{6}$ rings form instead. 
We also checked the possibility of obtaining heteroatomic chalcogen rings based on $(\mathrm{CuBr})_{2} \mathrm{Se}_{6}$ and on $(\mathrm{CuI})_{2} \mathrm{Se}_{6}$. These investigations were expected to provide some insight in the crystal chemistry of these compounds. No reasons were known why these materials crystallize in different structure types. Contrary to the expectation at least 50 percent of the selenium in the rings can be replaced by tellurium, whereas only about a maximum of 20 percent of the selenium can be substituted by sulfur. ${ }^{[30]}$ These heteroatomic six-membered chalcogen rings are structurally disordered and thus no full crystallographic characterization is possible by X-ray diffraction methods. This behavior was not expected for the CuXQQ' compounds. Both in $(\mathrm{CuBr})_{2} \mathrm{Se}_{6}$ and in $(\mathrm{CuI})_{2} \mathrm{Se}_{6}$ different chalcogen positions are present. That is, two thirds of the selenium atoms are bonded to copper, whereas one third has only covalent bonds to further selenium atoms (Figure 10). However, only a slight preference is found for the different crystallographic positions. That is, the positions providing contacts to copper and those not bonded to copper are almost equally occupied, regardless of whether sulfur or
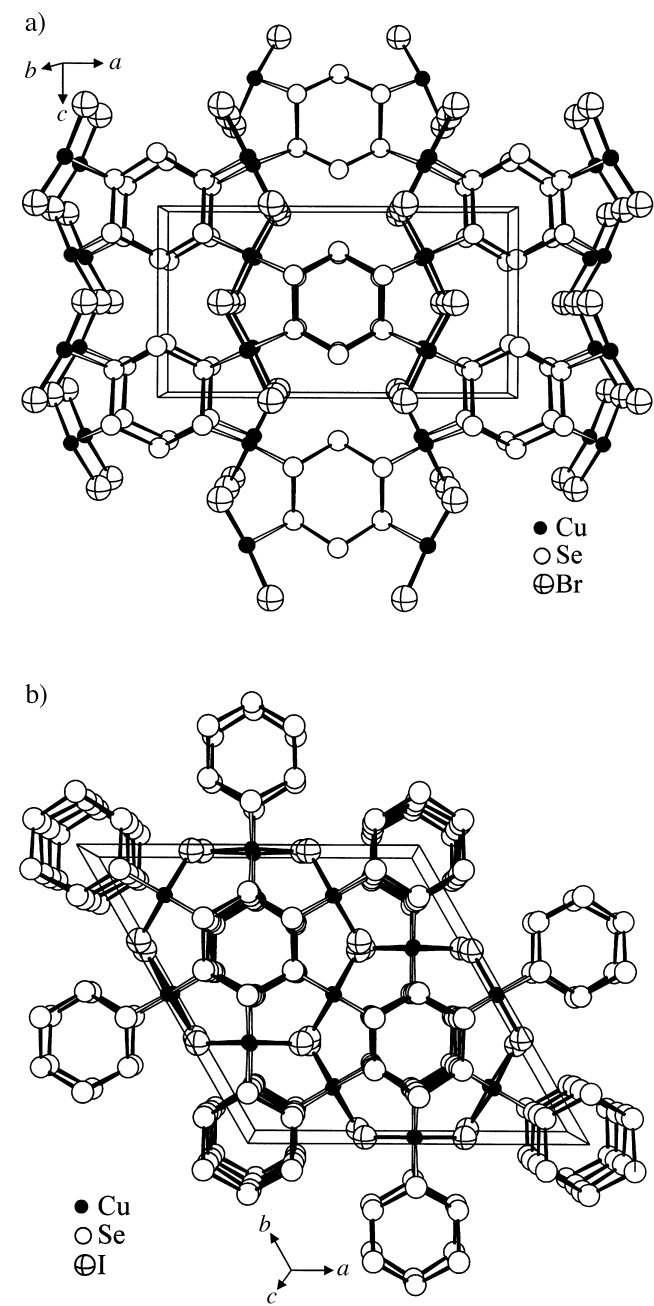

Figure 10. Crystal structures of a) $(\mathrm{CuBr})_{2} \mathrm{Se}_{6}{ }^{[3 \mathrm{a}]}$ and b) $(\mathrm{CuI})_{2} \mathrm{Se}_{6} \cdot{ }^{\left[{ }^{3 b}\right]} \mathrm{In}$ both compounds two-thirds of the chalcogen atoms are bonded to copper and further chalcogen atoms, whereas one-third exhibits only covalent bonds to further selenium atoms. The chalcogen rings in these structure types are stacked in a different manner due to the different volume fractions $V_{\mathrm{CuX}} / \mathrm{V}_{\left(\mathrm{Q}^{\prime} \mathrm{Q}^{\prime}\right)_{6}}$. tellurium is incorporated in the ring molecules. Nevertheless, some insight into the crystal chemistry of these $(\mathrm{CuX})_{2} \mathrm{Q}_{6}$ compounds can be derived from these investigations. The $(\mathrm{CuBr})_{2} \mathrm{Se}_{6}$ structure type ${ }^{[3 \mathrm{a}]}$ transforms into the $(\mathrm{CuI})_{2} \mathrm{Se}_{6}$ structure type ${ }^{[3 b]}$ with an increasing amount of sulfur in the rings. From combined powder and single-crystal X-ray investigations a critical composition of about 10 percent of sulfur content in the rings can be derived for the transition point. ${ }^{[31]}$ Therefore, it can be concluded that the volume fraction of the copper halide and the chalcogen ring present, that is, $V_{\mathrm{CuX}} /$ $\mathrm{V}_{\left(\mathrm{Q} / \mathrm{Q}^{\prime}\right)_{6}}$, determines which structure type results. Evidently, the chemical differences between $\mathrm{CuBr}$ and $\mathrm{CuI}$ play only a minor role in these considerations.

\section{Composite Materials of Copper Halides and Copper Thiometalates}

The copper halide matrix cannot be only used for the synthesis of neutral molecules but provides also access to compounds based on complex thioanions. These compounds are of special interest in terms of ionic conductivity since the polarizibility of the chalcogenide ions is supposed to be much higher than that of the neutral ligands described above. We obtained the first example of this series during attempts to synthesize CuISTe, a compound that is still missing from the CuXQQ' group. Black shiny crystals of $(\mathrm{CuI})_{3} \mathrm{Cu}_{2} \mathrm{TeS}_{3}$ resulted instead. ${ }^{[32]} \mathrm{A}$ redox reaction occurred in the course of this reaction, yielding discrete complex $\left[\mathrm{TeS}_{3}\right]^{2-}$ ions instead of the neutral polymers ${ }_{\infty}^{1}[\mathrm{STe}]$. In the crystal structure of $(\mathrm{CuI})_{3}$ $\mathrm{Cu}_{2} \mathrm{TeS}_{3}$ these thiotellurate(Iv) ions are arranged in layers with their dipoles oriented parallel. In adjacent layers they are oriented antiparallel. These layers are separated by iodide ions. This anionic framework provides numerous voids of appreciable size for copper ions. A pronounced disorder of copper results and at least eleven different positions are partially occupied in a statistical way.

A new ordered variant of the zinc blende structure type results when not yet known " $\mathrm{Cu}_{2} \mathrm{TeS}_{3}$ " is combined with $\mathrm{CuCl}^{[33]}$ In this semiconducting material both cations and anions are ordered in a 3:1 fashion (Figure 11). The deviations

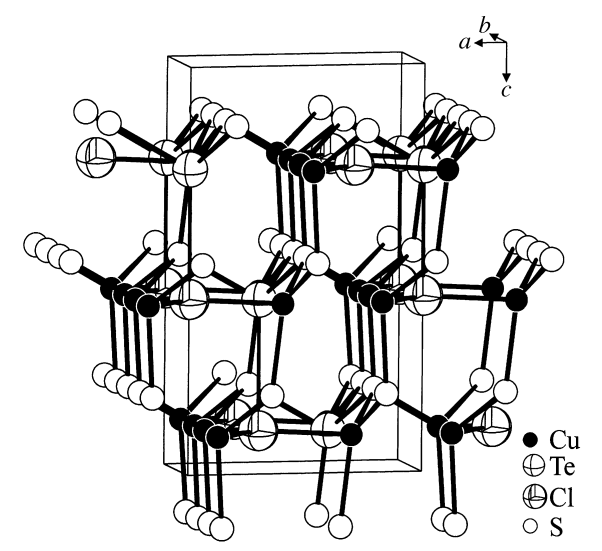

Figure 11. $\mathrm{CuClCu}_{2} \mathrm{TeS}_{3}$ shows an ordered arrangement of cations and anions which results in a new variant of the zinc blende structure type. Owing to an excess of two valence electrons, chlorine and tellurium are only three-coordinate and both ions bear a lone pair of electrons. 
from the ideal zinc blende structure type are due to this ordered distribution of the ions. Another reason which is much more important for the distortion is the valence electron count of this material. For a regular tetrahedral structure four valence electrons per atom are needed. In $\mathrm{CuClCu}_{2} \mathrm{TeS}_{3}$ 34 electrons are available for eight atoms, and therefore one bond is broken. As a result there are lone pais of electrons located both on chlorine and tellurium and the distance $d\left(\mathrm{Te}^{4+}-\mathrm{Cl}^{-}\right)$is longer than the distance $d\left(\mathrm{~S}^{2-}-\mathrm{Cl}^{-}\right)$.

Comparing $(\mathrm{CuI})_{3} \mathrm{Cu}_{2} \mathrm{TeS}_{3}$ and $\mathrm{CuClCu}_{2} \mathrm{TeS}_{3}$ might lead to the assumption that also a compound $(\mathrm{CuBr})_{x} \mathrm{Cu}_{2} \mathrm{TeS}_{3}$ possibly with $x=2$ might exist. However, our attempts to synthesize a composite of $\mathrm{CuBr}$ and " $\mathrm{Cu}_{2} \mathrm{TeS}_{3}$ " failed. Instead, the unforeseen mixed-valent compound $\mathrm{CuBrCu}_{1.2} \mathrm{TeS}_{2}$ was obtained. ${ }^{[34]}$ Therein the novel radical anion $\left[\mathrm{TeS}_{2}\right]^{\cdot-}$ is found besides $\left[\mathrm{TeS}_{2}\right]^{2-}$ polyanions. The radical character of $\left[\mathrm{TeS}_{2}\right]^{\cdot-}$ was proved by X-ray crystallography and ESR spectroscopy (Figure 12). From the ESR investigations it can be concluded

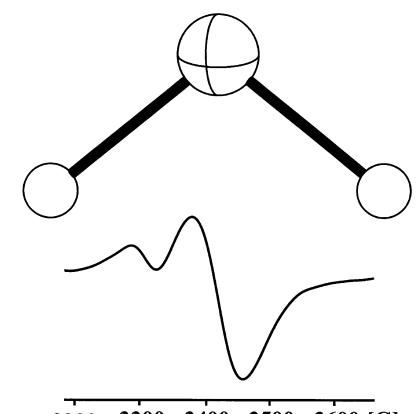

Figure 12. Structure of the radical anion $\left[\mathrm{TeS}_{2}\right]^{\cdot-}$ along with the ESR spectrum recorded at $3.5 \mathrm{~K}$. At higher temperatures the signal cannot be detected due to fast relaxation processes.

unambiguously that copper is exclusively present as $\mathrm{Cu}^{+}$. No hints of hyperfine splitting, which would have indicated the presence of $\mathrm{Cu}^{2+}$ were detected in the spectrum. The composition of $\mathrm{CuBrCu}_{1.2} \mathrm{TeS}_{2}$ immediately indicates the mixed-valent character of this compound. Since the ESR spectra show that copper is monovalent it can be concluded that some portion of the $\left[\mathrm{TeS}_{2}\right]$ units bears two electrons, that is, there are also polychalcogenide ions $\left[\mathrm{TeS}_{2}\right]^{2-}$ present besides the radical anions $\left[\mathrm{TeS}_{2}\right]^{\cdot-}$. However, no ordered distribution of the two different species and also of copper ions in the van der Waals gap was detected by X-ray crystallography.

The advantage of the concept becomes obvious once more when the close relationships between $(\mathrm{CuI})_{3} \mathrm{Cu}_{2} \mathrm{TeS}_{3}$ and $(\mathrm{CuI})_{2} \mathrm{Cu}_{3} \mathrm{SbS}_{3}{ }^{[35]}$ are considered. The more negative charge of the $\left[\mathrm{SbS}_{3}\right]^{3-}$ unit as compared to the $\left[\mathrm{TeS}_{3}\right]^{2-}$ unit is compensated by an additional copper ion in the copper metalate part of this composite material. However, the total number of copper ions is the same for both compounds and thus, one iodide ion is missing in $(\mathrm{CuI})_{2} \mathrm{Cu}_{3} \mathrm{SbS}_{3}$ in comparison to $(\mathrm{CuI})_{3} \mathrm{Cu}_{2} \mathrm{TeS}_{3}$. At a first glance both compounds have quite different crystal structures. Nevertheless, they both exhibit layers ${ }_{\infty}^{2}\left[\mathrm{Cu}_{3} \mathrm{MS}_{3} \mathrm{I}_{2}{ }^{x-}\right]$ consisting of $\left[\mathrm{MS}_{3}\right]^{n-}$ units, copper ions located in tetrahedral voids, and copper ions with an almost planar threefold coordination (Figure 13). The
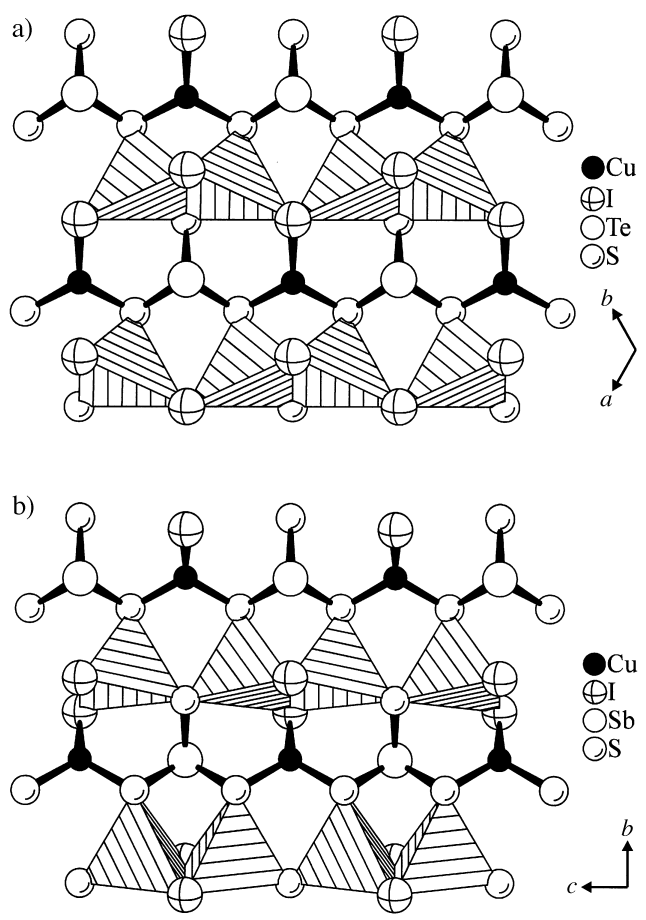

Figure 13. Comparison of the polyanionic layers ${ }_{x}^{2}\left[\mathrm{Cu}_{3} \mathrm{MS}_{3} \mathrm{I}_{2}{ }^{x-}\right]$ observed in a) $(\mathrm{CuI})_{3} \mathrm{Cu}_{2} \mathrm{TeS}_{3}$ and b) $(\mathrm{CuI})_{2} \mathrm{Cu}_{3} \mathrm{SbS}_{3}$. They look very similar at first glance but the atomic arrangement differs significantly.

differences between the crystal structures result from both the different features observed in the layers and the different way of stacking of the layers.

\section{Ionic Conductivity and Reactivity}

A number of compounds formed by $\mathrm{CuX}$ and phosphorus is available as shown above, and thus it becomes possible to estimate the main trends concerning their ionic conductivity and their reactivity. From impedance spectroscopic data it can be concluded that the highest conductance is provided by those compounds with a high copper halide content. That is, the highest conductivities are observed for $(\mathrm{CuI})_{8} \mathrm{P}_{12}[4,17,36]$ and for $(\mathrm{CuBr})_{10} \mathrm{Cu}_{2} \mathrm{P}_{20}{ }^{[17,36]}$ If the ratio $\mathrm{CuX} / \mathrm{P}$ becomes smaller the ionic conductivity decreases and is even negligible in the case of $(\mathrm{CuI})_{2} \mathrm{CuP}_{15}$. This material is supposed to be mainly a semiconductor. ${ }^{[17]}$ The ionic conductivity and mobility are strongly correlated with the rate and the extent of ion exchange reactions. Thus, the ionic conductivity can be estimated from the reactivity of the materials towards an aqueous silver nitrate solution. ${ }^{[4]}$ Qualitative exchange rates and ionic conductivity data of various compounds show a good correlation. ${ }^{[17]}$ Relatively high copper ion conductance was found for compounds of the CuXTe type. The ionic conductivities of these materials show a pronounced anisotropy which is due to the strong anisotropy of this structure type. Thus the conductivity parallel to the tellurium chains is more than one order of magnitude higher than that perpendicular to these chains. ${ }^{[1 b]}$ The reason for this anisotropy is the existence of diffusion pathways for copper in one direction and the separation of these pathways in the perpendicular 
direction. A low or an even negligible ionic conductivity is found for compounds with a higher chalcogen content, that is, for the compositions $\mathrm{CuXQ}_{2}$ and $(\mathrm{CuX})_{2} \mathrm{Q}_{6}$. The decreasing number of mobile atoms can be regarded as the major reason for this finding, which is similar to that for the series $(\mathrm{CuX})_{m} \mathrm{P}_{n}$. The most interesting compounds of the series under discussion are the composite materials consisting of copper halides and copper thiometalates, at least when the ionic conductivity is considered. Owing to the combination of the highly polarizable anions $\mathrm{I}^{-}$and $\mathrm{S}^{2-}$ and a large number of nearly energetically equal sites for the copper atoms, these materials can be regarded as the best copper ion conductors known to date. ${ }^{[37]}$ Figure 14 shows an Arrhenius plot of the

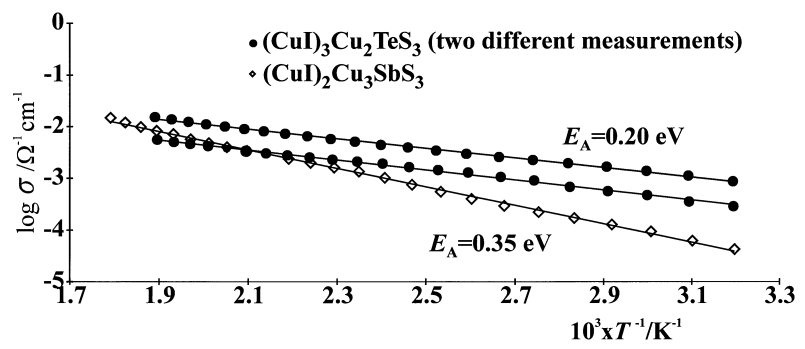

Figure 14. Arrhenius type representation of the specific conductivities of $(\mathrm{CuI})_{3} \mathrm{Cu}_{2} \mathrm{TeS}_{2}$ and $(\mathrm{CuI})_{2} \mathrm{Cu}_{3} \mathrm{SbS}_{3}$. The combination of a high conductivity and a low activation energy $E_{\mathrm{A}}$ provides a good characteristic especially in the room-temperature regime.

specific ionic conductivities of $(\mathrm{CuI})_{3} \mathrm{Cu}_{2} \mathrm{TeS}_{2}$ and $(\mathrm{CuI})_{2}$ $\mathrm{Cu}_{3} \mathrm{SbS}_{3}$. The influence of the arrangement of vacant positions and especially of the existence or the nonexistence of bottlenecks for the mobile copper ions, that is, octahedral voids which have to be passed by copper, becomes evident from the properties of the chemically closely related pair $(\mathrm{CuI})_{3} \mathrm{Cu}_{2} \mathrm{TeS}_{2}$ and $(\mathrm{CuI})_{2} \mathrm{Cu}_{3} \mathrm{SbS}_{3}$. In the case of $(\mathrm{CuI})_{2}$ $\mathrm{Cu}_{3} \mathrm{SbS}_{3}$ the activation energy $E_{\mathrm{A}}$ is $0.35 \mathrm{eV}$ which is in the same range as in the case of $\mathrm{Cu}_{3} \mathrm{SbS}_{3} \cdot{ }^{[38]}$ The bottlenecks for the diffusion of copper are distorted octahedral voids $S_{6}$ in both compounds. For $\mathrm{Cu}_{3} \mathrm{SbS}_{3}$ an activation energy of about $0.27 \mathrm{eV}$ was estimated from high-temperature $\mathrm{X}$-ray data for a jump of copper through this empty octahedron. In the crystal structure of $(\mathrm{CuI})_{3} \mathrm{Cu}_{2} \mathrm{TeS}_{3}$ no octahedral voids are present to hinder a three-dimensional diffusion of copper. In addition, numerous closely neighbored sites providing the preferred coordination numbers three and four are available. As a consequence the activation energy for $(\mathrm{CuI})_{3} \mathrm{Cu}_{2} \mathrm{TeS}_{3}$ is only $E_{\mathrm{A}}=0.2 \mathrm{eV}$, resulting in the aforementioned high conductivity.

\section{Conclusion}

The exploration of adduct compounds based on copper halides and neutral or low-charged molecules of Group 15 and Group 16 elements has led to new insight into the coordination chemistry of these elements. The resulting compounds may be regarded as a combination of the copper halide matrix and sections from new modifications of the incorporated elements. However, attempts to separate the matrix from the polymers has always resulted in amorphous products to date. Thus, the goal of preparing these new modifications, especially of phosphorus, in crystalline solids has yet to be achieved. However, this synthetic approach gives access to polymers or cage molecules that have been calculated to be thermodynamically stable. In the case of the $\mathrm{P}_{4} \mathrm{Se}_{4}$ cage molecule numerous former attempts to obtain it as a well-defined material failed when mixtures of phosphorus and selenium were combined at various temperatures. It can be concluded that the addition of copper halides to the reaction mixtures just helps to transfer the reaction products to a crystalline state. Adducts of other metal halides to similar neutral molecules are limited to a few examples such as $\left(\mathrm{PdCl}_{2}\right) \mathrm{Se}_{6}{ }^{[39]}$ and $\left(\mathrm{NbCl}_{5}\right)_{2} \mathrm{P}_{4} \mathrm{~S}_{4} \cdot{ }^{[24]}$ Advantages of the copper halides over analogous systems with silver or gold halides are certainly the relatively small ionic radius of $\mathrm{Cu}^{+}$ and also the enormous coordination flexibility of the $\mathrm{Cu}^{+}$ion. In addition the combination of copper halides with copper thiometalates provides access to a new class of copper ion conductors. New compounds with the heavier chalcogens are now the focus of our research with the aim of further increasing their high conductivity.

\section{Acknowledgement}

The author thanks Prof. Deiseroth for his continuous support, and especially his co-workers Dr. E. Freudenthaler, Dr. S. Zimmerer, S. Reiser, and T. Nilges for their engaged collaboration in this project. This work was supported by the Deutsche Forschungsgemeinschaft and the Fonds der Chemischen Industrie.

[1] a) W. Milius, Z. Anorg. Allg. Chem. 1990, 586, 175; b) P. M. Carkner, H. M. Haendler, J. Solid State Chem. 1976, 18, 183; U. von Alpen, J. Fenner, B. Predel, A. Rabenau, G. Schluckebier, Z. Anorg. Allg. Chem. 1978, 438, 5; R. Bachmann, K. D. Kreuer, A. Rabenau, H. Schulz, Acta Crystallogr. Sect. B 1982, 38, 2361; c) J. Fenner, A. Rabenau, Z. Anorg. Allg. Chem. 1976, 426, 7.

[2] a) J. Fenner, Acta Crystallogr. Sect. B 1976, 32, 3084; b) W. Milius, $Z$. Naturforsch. Sect. B 1989, 44, 990.

[3] a) H. M. Haendler, P. M. Carkner, S. M. Boudreau, R. A. Boudreau, J. Solid State Chem. 1979, 29, 35; T. Sakuma, T. Kaneko, T. Kurita, H. Takahashi, J. Phys. Soc. Jpn. 1991, 60, 1608; b) W. Milius, A. Rabenau, Mater. Res. Bull. 1987, 22, 1493.

[4] M. H. Möller, W. Jeitschko, J. Solid State Chem. 1986, 65, 187.

[5] U. Thewalt, B. Müller, Z. Naturforsch. Sect. B 1982, 37, 828.

[6] A. Rabenau, Angew. Chem. 1985, 97, 1017; Angew. Chem. Int. Ed. Engl. 1985, 24, 1026.

[7] A. Pfitzner, E. Freudenthaler, Angew. Chem. 1995, 107, 1784; Angew. Chem. Int. Ed. Engl. 1995, 34, 1647.

[8] A. Pfitzner, E. Freudenthaler, Z. Naturforsch. Sect. B 1997, 52, 199.

[9] S. Böcker, M. Häser, Z. Anorg. Allg. Chem. 1995, 621, 258.

[10] H. Thurn, H. Krebs, Acta Crystallogr. Sect. B 1969, 25, 125.

[11] M. H. Möller, W. Jeitschko, Z. Anorg. Allg. Chem. 1982, 491, 225.

[12] A. Pfitzner, E. Freudenthaler, Z. Kristallogr. 1995, 210, 59.

[13] E. Freudenthaler, A. Pfitzner, Z. Kristallogr. 1997, 212, 103.

[14] H. G. von Schnering, W. Hönle, Chem. Rev. 1988, 88, 243.

[15] E. Freudenthaler, Ph.D. thesis, Universität Siegen, 1997.

[16] O. Olofsson, J. Gullman, Acta Chem. Scand. 1971, 25, 1327.

[17] E. Freudenthaler, A. Pfitzner, Solid State Ionics 1997, 101-103, 1053.

[18] M. Ruck, Z. Anorg. Allg. Chem. 1994, 620, 1832.

[19] A. Pfitzner, S. Reiser, Inorg. Chem. 1999, 38, 2451.

[20] Y. Monteil, H. Vincent, Z. Anorg. Allg. Chem. 1975, 416, 181.

[21] D. Lathrop, H. Eckert, J. Phys. Chem. 1989, 93, 7895.

[22] G. M. S. Lister, R. Jones, J. Phys.: Condens. Matter 1989, 1, 6039. 
[23] D. Adam, B. Herrschaft, H. Hartl, Z. Naturforsch. Sect. B 1991, 46, 738.

[24] H. Nowottnick, K. Stumpf, R. Blachnik, H. Reuter, Z. Anorg. Allg. Chem. 1999, 625, 693 .

[25] A. Pfitzner, S. Reiser, H. J. Deiseroth, Z. Anorg. Allg. Chem. 1999, $625,2196$.

[26] A. Pfitzner, S. Zimmerer, Z. Anorg. Allg. Chem. 1995, 621, 969.

[27] A. Pfitzner, S. Zimmerer, Z. Anorg. Allg. Chem. 1996, 622, 853.

[28] A. Rabenau, H. Rau, G. Rosenstein, Z. Anorg. Allg. Chem. 1970, 374, 43.

[29] A. Pfitzner, T. Nilges, H.-J. Deiseroth, Z. Anorg. Allg. Chem. 1999, 625, 201.

[30] A. Pfitzner, S. Zimmerer, Z. Kristallogr. 1997, 212, 203.

[31] A. Pfitzner, T. Nilges, unpublished results.
[32] A. Pfitzner, S. Zimmerer, Angew. Chem. 1997, 109, 1031; Angew. Chem. Int. Ed. Engl. 1997, 36, 982.

[33] A. Pfitzner, Inorg. Chem. 1998, 37, 5164.

[34] A. Pfitzner, F. Baumann, W. Kaim, Angew. Chem. 1998, 110, 2057; Angew. Chem. Intl. Ed. 1998, 37, 1955.

[35] A. Pfitzner, Chem. Eur. J. 1997, 3, 2032.

[36] E. Freudenthaler, A. Pfitzner, D. C. Sinclair, Mater. Res. Bull. 1996, 31(2), 171.

[37] A. Pfitzner, S. Reiser, T. Nilges, W. Kockelmann, J. Solid State Chem. 1999, 147, 170 .

[38] A. Pfitzner, Z. Kristallogr. 1998, 213, 228.

[39] K. Neininger, H. W. Rotter, G. Thiele, Z. Anorg. Allg. Chem. 1996, $622,1814$. 